\title{
PLATAFORMA WIGGIO E ENSINO DE LÍNGUAS: UMA PROPOSTA DE INTERAÇÃO NO AMBIENTE VIRTUAL
}

\author{
Limerce Ferreira LOPES \\ Instituto Federal de Goiás/Câmpus Goiânia
}

\section{RESUMO:}

Essa comunicação visa a apresentar um projeto desenvolvido no Instituto Federal de Goiás, Câmpus Goiânia, inicialmente com uma turma do curso Técnico Integrado de Controle Ambiental e uma turma do curso superior de Licenciatura em História, na disciplina de Língua Espanhola. Nosso objetivo consistiu em utilizar a plataforma Wiggio, durante o ano letivo, como um espaço de aprendizagem assíncrona e, assim, verificar a potencialidade e as contribuições dessa ferramenta no processo de ensino-aprendizagem de língua espanhola. Desse modo, para promover a interação iniciada em sala de aula, adotamos as ferramentas disponibilizadas pela Wiggio, tais como: conferência, gravação de vídeos, fóruns, calendário compartilhado, mensagens de texto, compartilhamento de arquivos etc. Ao término de cada sequência de atividades, os alunos avaliaram as ferramentas utilizadas com o intuito de verificar sua efetividade no processo de compreensão das habilidades trabalhadas. Espera-se, com este projeto, contribuir para a motivação dos alunos em relação às aulas de línguas, além de fomentar a integração das novas tecnologias no dia a dia de sala de aula.

PALAVRAS-CHAVE: Ensino. Língua Estrangeira. Tecnologia.

ABSTRACT: This oral presentation aim to present a project developed at Instituto Federal de Goiás, Câmpus Goiânia, at first with a Integrated Environmental Control Technician Course class and a Bachelor of History class, in the Spanish Language subject. Our goal was to use the Wiggio platform during the school year as an asynchronous learning space and thus to verify the potentiality and contributions of this tool in the Spanish language teaching-learning process. Thereby to promote interaction initiated in the classroom, we have adopted the tools provided by Wiggio, such as: conference, video recording, forums, shared calendar, text messages, file sharing, etc. At the end of each sequence of activities, the students evaluated the tools used in order to verify their effectiveness in the process of understanding the skills worked. With this project, we hope to contribute to the motivation of students in relation to language's classes, as well as to promote the integration of new technologies in a daily class.

KEY WORDS: Teaching. Foreign language. Technology.

\section{Introdução}

O advento das novas tecnologias fomenta, cada vez mais, discussões e novas possibilidades de pensar e realizar estratégias em sala de aula. Com o surgimento da informática e da telemática, o conhecimento passou a ser rapidamente disseminado entre todos os que o utilizam, tornando possível o acesso rápido a informações, pesquisas etc. Como consequência, essas informações contribuem para que o aluno desenvolva a habilidade de autoaprendizagem, uma vez que essa nova forma de selecionar e produzir conhecimento exige um movimento constante e dialético de saber "apreender" essas informações, as quais, 
muitas vezes, precisam ser lidas e compreendidas criticamente por eles, sem a ajuda de um professor. Para Masetto (2000, p. 137), a construção desse conhecimento possibilita uma integração dos alunos em atividades que vão além dos momentos de aula, nos períodos "entreaulas", tornando possível "o desenvolvimento da criticidade para se situar diante de tudo o que se vivencia por meio do computador, da curiosidade para buscar coisas novas, da criatividade para se expressar e refletir".

Neste sentido, o uso da tecnologia pode ser compreendido como um "meio" importante para que o professor promova o acesso ao conhecimento e estimule seus alunos a buscar, por meio da leitura, da pesquisa, da realização de atividades interativas, uma forma de colaborar com o desenvolvimento do processo de aprendizagem. A tecnologia tem sua importância como instrumento significativo no desenvolvimento do processo autônomo perante o conhecimento, uma vez que o aluno precisa, neste contexto, assumir o papel de aprendiz ativo. Isso significa mudar uma mentalidade construída ao longo da história, pois o aluno deve trabalhar individualmente para aprender e colaborar com a aprendizagem dos colegas, isto é, com o grupo. Segundo Gutiérrez Pérez e Prieto Castillo (1999, p. 42), esse novo modo de conceber as interações (aluno-professor-aluno) permite o desenvolvimento da corresponsabilidade no processo de aprendizagem, uma vez que "não se pode educar para conviver se não se educa na cooperação e na participação coletiva".

Desta forma, a tecnologia, além de possibilitar todos os aspectos acima levantados, somente terá importância se o seu uso for adequado para facilitar o alcance dos objetivos que, nesse caso, serão os de aprendizagem. Nesse contexto, este relato de experiência visa a apresentar um projeto que vem sendo desenvolvido no Instituto Federal de Goiás, Câmpus Goiânia, inicialmente com uma turma do curso Técnico Integrado de Controle Ambiental e com uma turma do curso superior de Licenciatura em História, na disciplina de Língua Espanhola. Para tal, utilizamos a plataforma Wiggio, um Ambiente Virtual de Aprendizagem - AVA, como "meio" para promover a interação entre os alunos por meio de atividades iniciadas em sala de aula e, posteriormente, realizadas na plataforma, tais como conferências, gravação de vídeos, fóruns, calendário compartilhado, mensagens de texto $\mathrm{e}$ compartilhamento de arquivos.

Assim, este projeto justifica-se pela necessidade de integrar o uso das novas tecnologias como metodologia nas aulas de língua espanhola, a fim de contribuir para o desenvolvimento das habilidades previstas na ementa do curso. Para tal fim, utilizamos a plataforma Wiggio durante o ano letivo como um espaço de aprendizagem assíncrona e, assim, pudemos verificar, por meio de feedbacks, a potencialidade e contribuições dessa ferramenta no processo de ensino-aprendizagem. Para nortear a pesquisa, estabelecemos os seguintes objetivos específicos: apresentar o projeto de pesquisa aos alunos, principalmente os objetivos a serem alcançados; apresentar aos alunos a plataforma Wiggio e suas respectivas ferramentas; cadastrar os alunos na plataforma, bem como inseri-los em grupos de discussão; expor aos alunos as regras de convivência nesse AVA ("netiqueta"); conhecer os nomes, em espanhol, das ferramentas disponibilizadas pela plataforma; propor diferentes atividades assíncronas referentes aos conteúdos apresentados em sala de aula; observar as ferramentas mais utilizadas pelos alunos na realização das atividades propostas; aplicar questionário de autoavaliação das ferramentas, após as atividades, com o intuito de elencar no discurso dos alunos as contribuições da plataforma para o processo de aprendizagem de língua espanhola. 
Espera-se, com este projeto, contribuir para a motivação dos alunos em relação às aulas de línguas, além de fomentar a integração das novas tecnologias no dia a dia de sala de aula.

\section{Revisão de Literatura}

O uso das novas tecnologias da informação e comunicação, na atualidade, tem contribuído de modo significativo para a construção do conhecimento e a formação dos indivíduos. Na escola, os alunos estão cada dia mais conectados à realidade virtual, o que exige, nesse novo cenário, que a instituição se adapte às novas práticas e, por conseguinte, consiga aproximá-las da realidade do aluno. Dias (2012) aborda essa necessidade de integração entre ensino e tecnologia:

A chegada cada vez mais rápida e intensa das tecnologias (com o uso cada vez mais comum de computadores, Ipods, celulares, tablets etc) e de novas práticas sociais de leitura e de escrita (condizentes com os acontecimentos contemporâneos e com os textos multissemióticos circulantes) requerem da escola trabalhos focados nessa realidade (p. 99).

Daí que o professor deve inovar em suas práticas, valorizar o conhecimento prévio do aluno, planejar estratégias que possam trazer esse "conhecimento virtual" para subsidiar os conteúdos ensinados em sala de aula, pois a possibilidade de construir juntos o conhecimento, por meio das ferramentas disponíveis na internet, difunde novos modos de aprender, novas formas de conceber o conhecimento, tornando a aprendizagem, assim, uma experiência mais significativa.

Nesse sentido, o professor pode utilizar vários recursos disponíveis online em sua prática de sala de aula. Uma delas é o AVA, que permite uma interação assíncrona e síncrona entre alunos e professores por meio de diversas ferramentas disponibilizadas. Esse ambiente, caracterizado como cooperativo, automatizado e interativo, pressupõe a presença de diversos autores, como professor/aluno, professor/equipe, professor/grupo de alunos etc., podendo ser configurado segundo os objetivos do professor.

Os recursos tecnológicos tendem a se apresentar como o habitat de muitos alunos, os conhecidos "nativos digitais", isto é, eles já sabem utilizá-los, estão familiarizados com vários recursos e os acessam com frequência. Por isso, nas aulas onde o computador se faz presente, o aluno participa mais ativamente, compartilha suas experiências, contribui para que os outros também elaborem seus saberes. Para confirmar tal assertiva, basta colocá-los diante do computador para verificar que o conhecimento que apresentam em diferentes ambientes digitais é, na maioria das vezes, maior que o conhecimento do professor, o que pode gerar uma insegurança por parte deste. Por isso, é comum perceber nos discursos de docentes alguma resistência em relação ao uso das tecnologias, justamente em decorrência do descrédito que se dá às contribuições dessa prática ao processo de aprendizagem e por se tratar, muitas vezes, de um "território" ainda desconhecido do professor. Sem dúvida, os recursos tecnológicos nunca substituirão o trabalho docente, mas sim ampliarão as possibilidades de fomentar a interação, a difusão do conhecimento e a motivação no processo 
de ensino. Por isso, o professor precisa buscar nesses recursos um aliado que, integrado às suas práticas, contribuirá para motivar e envolver os alunos no processo colaborativo de construção do conhecimento.

Dentre os vários recursos disponíveis, os AVA cumprem a tarefa de auxiliar o sujeito na construção do conhecimento e são utilizados como um espaço de interação, tanto para quem elabora estratégias de aprendizagem quanto para quem as utiliza. É nesse sentido que optamos por inserir essa ferramenta nas aulas de língua espanhola, porque acreditamos na sua potencialidade para otimizar nossas aulas presenciais e contribuir para que os alunos construam o conhecimento de modo significativo.

Essa interação proporcionada pelo AVA contribui para que os alunos pesquisem, compreendam e elaborem o conhecimento por meio da mediação tecnológica. Isto é, os alunos estão todo o tempo realizando as atividades e buscando informações em outros links, sites etc., assim, a construção dos saberes alcança uma dimensão que perpassa aspectos talvez não explorados no ensino presencial, tais como a imagem, o som, a interação em tempo real e o imaginário. Por isso, o uso das novas tecnologias deve fomentar a "valorização da autoaprendizagem, incentivar a formação permanente, a pesquisa de informações básicas e das novas informações, o debate, a discussão, o diálogo, o registro de documentos" (MASETTO, 2000, p. 153-154).

Dessa forma, combinar atividades presenciais e a distância ajuda os alunos a desenvolver habilidades de aprendizagem autônoma e cooperativa, uma vez que não há como vincular o conhecimento apenas à escola, como um saber fechado e acabado; ao contrário, ele pode ser acessado a qualquer momento, quando se trata de ciberespaço. Por outro lado, a realização dessas práticas que requerem a integração do ensino às tecnologias exige do professor um novo modo de pensar a educação, e isso implica romper com o paradigma tradicional que mantém professores e alunos distantes. (Re)pensar a educação, nessa nova perspectiva, significa conceber o uso da tecnologia não como algo "exógeno à docência, mas inerente a ela e necessário ao processo abrangente de formação integral do ser humano" (GARCIA et al., 2011, p. 80). Levando-se em consideração essa afirmação, é importante que o professor tenha um grau de letramento digital que lhe permita empregar com desenvoltura os conhecimentos relativos ao código das modalidades escrita e oral da língua às mais variadas situações sociais em ambientes digitais e que, portanto, ele demonstre ser um profissional crítico, reflexivo e competente no uso das novas tecnologias.

Dessa maneira, consideramos que a realização deste projeto configura-se como desafio diante das dificuldades que encontramos no processo de instauração dessas práticas. A inovação incomoda e traz consigo medo e ansiedade, tudo o que conhecemos é provisório, não existe um conhecimento definitivo e acabado; a realização desta proposta também está em permanente construção. Mas podemos assegurar que, a partir dos depoimentos dos alunos expressos nos questionários aplicados, a introdução das atividades envolvendo o AVA provocou mudanças na dinâmica das aulas, instigou a descoberta, despertou a motivação dos alunos em relação à língua espanhola, fomentou a pesquisa de aspectos que eles desconheciam, tanto linguísticos (vocabulário, gramática) quanto culturais (festas típicas etc.). O AVA contribuiu, em suma, para que as aulas de língua espanhola se tornassem mais significativas para os alunos, mesmo diante do contexto em que eles estão inseridos. 


\section{Metodologia}

Para esta pesquisa foram selecionadas, dentre as turmas em que ministramos aulas de Língua Espanhola no Instituto Federal Goiás, Câmpus Goiânia, uma de Licenciatura em História $\left(1^{\circ}\right.$ período) e outra de Controle Ambiental, Técnico Integrado ( $4^{\circ}$ período). A escolha das turmas foi aleatória. Os alunos de ambas estão estudando pela primeira vez a língua espanhola nessa instituição, tendo em vista que o idioma é ministrado apenas nas séries citadas. Portanto, trata-se de uma pesquisa, ainda em fase inicial, de natureza qualitativa, em virtude dos seguintes aspectos: a flexibilidade com que a pesquisa trata as perguntas e o foco da pesquisa; o modo como a investigação é conduzida; a forma como os discursos são analisados, possibilitando a realização de ajustes no processo de investigação diante da ocorrência de mudanças inesperadas, principalmente porque se trata de uma "instituição educacional" (DÖRNYEI, 2007).

Esta pesquisa envolve o uso da Wiggio, uma plataforma que permite juntar algumas ferramentas de trabalho colaborativo e gestão de projetos e apresentá-las de uma forma simples que não compromete a funcionalidade. Inicialmente, os alunos são cadastrados em um grupo pelo moderador (neste caso, a professora/pesquisadora) e, a partir desse cadastro, passam a ter acesso a todas as ferramentas e atividades postadas pelo moderador. Todos os membros do grupo podem enviar e-mails, textos e mensagens de voz; participar de conferências web; realizar chamadas em conferência e chat; compartilhar calendário; guardar, partilhar e editar pastas numa pasta comum, registrando-as em diferentes versões; postar opiniões sobre determinado tema proposto; seguir o curso das tarefas de grupo e dos recursos; gravar vídeos e notas de voz.

Nesse ambiente virtual, o professor de línguas pode utilizar os recursos para desenvolver várias habilidades comunicativas, tais como a produção textual (nos debates propostos), a expressão oral (na produção de notas de voz), a compreensão auditiva (quando assistem os vídeos postados) etc. Assim, a plataforma Wiggio é uma ferramenta interativa reflexiva (LAMY; GOODFELLOW, 1999), mediada pelo computador como base pedagógica. Isto é, esse meio eletrônico torna-se, nesse processo, um recurso didático de apoio à aquisição e produção de conhecimento e contribui para desenvolver habilidades importantes na aprendizagem de uma língua estrangeira.

Para a realização desse projeto, fez-se necessário apresentar a plataforma Wiggio aos alunos, os recursos disponibilizados nela e a funcionalidade destes no processo de ensinoaprendizagem. Assim, a metodologia utilizada foi planejada em três momentos: promover a ambientação dos alunos em relação ao uso da plataforma; propor a realização das atividades postadas a partir das ferramentas disponibilizadas; empreender a avaliação dos alunos em relação às ferramentas e atividades postadas na Wiggio.

No primeiro momento, realizamos a ambientação da plataforma com os alunos, ao cadastrá-los nos grupos, e posteriormente apresentamos a funcionalidade das ferramentas, esclarecendo aspectos como o primeiro acesso, mudança de senha, envio de mensagens, postagem de atividades etc. Esse primeiro momento ocorreu no laboratório de informática por meio de aula expositiva. 
No segundo momento, foram realizadas postagens de atividades relacionadas aos conteúdos vistos em sala de aula. Elas foram iniciadas em fevereiro de 2014 e encerradas em agosto de 2015 para os alunos de Licenciatura em História e em novembro de 2015 para os alunos do curso Técnico Integrado em Controle Ambiental. Estavam previstas duas propostas de atividades para cada conteúdo, mas, em virtude de imprevistos ocorridos durante o ano letivo (greve), tivemos que repensar o número de atividades. Nas propostas de atividades postadas, foram observadas e avaliadas a compreensão dos enunciados em língua espanhola, a compreensão auditiva e a capacidade de produzir pequenos textos (para os alunos de Controle Ambiental) e, principalmente, a capacidade dos alunos de avaliar as contribuições da plataforma no processo de aprendizagem em língua espanhola.

\section{Considerações (quase) finais}

Conforme discutimos ao longo deste trabalho, não há como negar que o sistema educacional hoje está tomando novos rumos. O acesso a informação está cada vez mais fácil, o uso das tecnologias cada vez maior, e o modo de pensar de nossas crianças e jovens demonstra o efeito dessa nova era. Assim, muitas pesquisas têm apresentado resultados sobre a importância e eficácia de usar ferramentas tecnológicas a favor das práticas de sala de aula, haja vista que estaremos contribuindo para que o conhecimento seja apreendido por nossos alunos de maneira mais significativa. Mas, para que isso ocorra, é necessária uma mudança de paradigma, isto é, repensar as práticas, o modo de interação, os papéis de alunos e professores e, principalmente, a própria formação docente. É preciso, em suma, romper com práticas tradicionais impregnadas na nossa memória discursiva e que contribuíram para a nossa formação profissional.

Vencer desafios e superar as nossas próprias limitações devem fazer parte da história de formação do professor. Portanto, como educadores, devemos sempre buscar novos modos de motivar nossos alunos a pensar, a estudar e a aprender, em um mundo tão cheio de atrativos, muitos deles maiores que a instituição escolar. Foi pensando nesses aspectos que formulamos esta proposta de projeto: instigar os alunos a conhecer melhor uma língua estrangeira (espanhol), a qual, diante de várias outras disciplinas que compõem a grade curricular (quinze para o TICA e oito para a LH), era apenas mais uma que eles precisariam estudar para cumprir as obrigações didático-metodológicas exigidas pela instituição. Então, fomentar a participação desses alunos no ambiente fora da sala de aula constitui um desafio que, para nós, pareceu mais fácil atrelando a ele as práticas realizadas no ambiente virtual, um habitat tão próprio dos alunos. Então, prepará-los para usar as ferramentas virtuais foi uma forma de levá-los a ter uma proximidade maior com a língua estrangeira, seja nos aspectos linguísticos, sintáticos, semânticos etc. Como já mencionamos, nada é permanente. Estamos construindo uma proposta que, acreditamos, pode dar muito certo se desenvolvida com outros grupos. Iniciamos um projeto-piloto, tivemos alguns atropelos não esperados, mas, até o momento, já estamos satisfeitos, pois algumas respostas dos alunos nos mostram que vale a pena o esforço de buscarmos uma aprendizagem mais significativa. 


\section{Referências}

DIAS, A. V. M. Hipercontos multissemióticos: para a promoção dos multiletramentos. In: ROJO, R. H.; ALMEIDA, E. M. (Org.). Multiletramentos na escola. São Paulo: Parábola Editorial, 2012. p. 95-122.

DÖRNYEI, Z. Research methods in applied linguistics. Oxford: Oxford University Press, 2007.

GARCIA, M. et al. Novas competências docentes frente às tecnologias digitais interativas. Teoria e Prática da Educação, Maringá, v. 14, n. 1, p. 79-87, jan./abr. 2011.

GUTIÉRREZ, P., F.; PRIETO, C.D. La mediación pedagógica: apuntes para una educación a distancia alternativa. Buenos Aires: Editorial La Crujía, 1999.

LAMY, M.N.; GOODFELLOW, R. "Reflective conversation" in the virtual language classroom. Language Learning \& Technology, v. 2, n. 2, p. 43-61, Jan. 1999.

MASETTO, M. T. Mediação pedagógica e o uso da tecnologia. In: MORÁN, J. M.; MASETTO, M. T.; BEHRENS, M. A. Novas tecnologias e mediação pedagógica. Campinas, SP: Papirus, 2000. p. 133-173.

MORÁN, J. M. O vídeo na sala de aula. Comunicação \& Educação. São Paulo, n. 2, p. 2735, jan./abr. 1995.

SERAFIM, M. L.; SOUSA, R. P. Multimídia na educação: o vídeo digital integrado ao contexto escolar. In: SOUSA, R. P.; MOITA, F. M. C. S. C.; CARVALHO, A. B. G. (Org.). Tecnologias digitais na educação. Campina Grande, PB: EDUEPB, 2011. p. 19-50. 